\title{
A Conjecture on Super Edge-Magic Total Labeling of 4-Cycle Books
}

\author{
Mudin Simanihuruk (D), ${ }^{1}$ Tri Atmojo Kusmayadi $\mathbb{D}^{2},{ }^{2}$ Baki Swita ${ }^{\mathbb{D}},{ }^{1}$ Minsi Romala $\left(\mathbb{D},{ }^{1}\right.$ \\ and Friska Damanik $\mathbb{D}^{1}$
}

${ }^{1}$ Mathematics Department, Universitas Bengkulu, Bengkulu 38371, Indonesia
${ }^{2}$ Mathematics Department, Universitas Sebelas Maret, Surakarta 57126, Indonesia

Correspondence should be addressed to Mudin Simanihuruk; mudinsimanihuruk@yahoo.com.au

Received 11 May 2021; Accepted 25 July 2021; Published 13 August 2021

Academic Editor: Sergejs Solovjovs

Copyright (c) 2021 Mudin Simanihuruk et al. This is an open access article distributed under the Creative Commons Attribution License, which permits unrestricted use, distribution, and reproduction in any medium, provided the original work is properly cited.

A graph $G$ is called cycle books $B[(4, m), 2]$ if $G$ consists of $m$ cycles $C_{4}$ with a common path $P_{2}$. Figueroa-Centeno, Ichishima, and Muntaner-Batle conjecture that the graph $B[(4, m), 2]$ is super edge-magic total if and only if $m$ is even or $m \equiv 5 \bmod (8)$. In this article, we prove this conjecture for $m \geq 36$ and $m=0 \bmod (2)$.

\section{Introduction}

For undefined terms and notations in this study, we follow Chartrand, Lesniak, and Peng [1]. Let $G$ be a graph with $V(G)$ and $E(G)$ be a set of vertices and edges, respectively. A graph $G$ is called a $(p, q)$ graph if $G$ has $p$ and $q$ number of vertices and edges, respectively. Kotzig and Rosa [2] defined that an edge-magic total labeling of $G$ is a bijective function $f$ : $V(G) \cup E(G) \longrightarrow\{1,2, \ldots, p+q\}$, such that $f(w)+f(w z)+$ $f(\mathrm{z})=k$ for any edge $w z \in E(G)$. Moreover, a super edgemagic total labeling is an edge-magic total labeling $f$, such that $f(V(G))=\{1,2, \ldots, \mathrm{p}\}$.

The notion of edge-magic total labeling of a graph is generalized to edge-antimagic total labeling of graphs. Let $\alpha \geq 0$ and $\beta \geq 0$ be integers. Let $W=\{w(x y): w(x y)=f$ $(x)+f(x y)+f(y), x y E(G)\}$. If $W$ forms an arithmetic sequence starting from $\alpha$ with common difference $\beta$, then $G$ is called $(\alpha, \beta)$ - edge antimagic total labeling. Moreover, if $f(V(G))=\{1,2, \ldots, \mathrm{p}\}$, then $G$ is called $\operatorname{super}(\alpha, \beta)-$ edge antimagic total labeling. Notice that when $\beta=0$, the $(\alpha, \beta)$ - edge antimagic total labeling of $G$ is the usual edgemagic total labeling of $G$ with $f(w)+f(\mathrm{wz})+f(\mathrm{z})=\alpha$ for any edge $w z \in E(G)$.
One of the most popular problems in the theory of graph labeling is super edge-magic total labeling of tree. Enomoto et al. [3] proposed the following conjecture.

Tree conjecture [3]: every tree is super $(\alpha, 0)-$ edge antimagic total labeling.

The tree conjecture is still an open problem; however, some authors proved that tree conjecture is true for some classes of tree. For example, Bhatti, Javaid and Hussain [4] and Raheem et al. [5] proved that tree conjecture is true for subdivision of caterpillar. Javaid, Bhatti, and Aslam [6] proved that tree conjecture is true for subdivision of stars. Other authors who studied tree conjecture can be found in Gallian [7].

Another popular problem in the theory of graph labeling is super edge-magic total labeling of a cycle book. A cycle book graph is constructed from some cycles either with the same or different order. Let $m \geq 1$ be any positive integer and let $C_{a}$ be the cycles of order $a$. A graph $G$ is called $a$-cycle books $B\left[\left(C_{a}, m\right), 2\right]$ if $G$ consists of $m$ cycles $C_{a}$ with a common path $P_{2}$. For $m=1$, we define $B\left[\left(C_{a}, m\right), 2\right]$ to be a cycle $C_{a}$. From now on, the graphs, $a$-cycle books $B\left[\left(C_{a}, m\right), 2\right]$ is denoted by $B[(a, m), 2]$.

Marr and Wallis ([8], Research problem 2.7, p.39) proposed the following problem. 
Problem 1. Are all graphs $B[(a, m), 2]$ edge-magic total (super edge-magic total)?

Graph $B[(a, m), 2]$ is constructed from some cycles $C_{a}$ of the same order. Swita et al. [9] contructed a graph from some cycles with different orders. A graph $(a, b)$ - cycle book $B[(a, m),(b, n), t]$ is constructed from some cycles $C_{a}$ and $\mathrm{C}_{b}$ with a common path $P_{t}$, a path of order $t$ with $m, n, a, b$, and $t$ as the positive integers.

Problem 2. Are all graphs $B[(a, m),(b, n), 2]$ edge-magic total (super edge-magic total)?

Both Problems 1 and 2 are interesting problems for at least the following two reasons. First reason is the solutions of Problems 1 and 2 that can be used to construct the secret sharing scheme in information technology. Reddy and Basha [10] and Imron et al. [11] used edge-magic total labeling of catepilar graphs to construct the secret sharing scheme. Baskoro, Simanjuntak, and Adithia [12] used edge-magic total labeling of star graphs to construct the secret sharing scheme.

The second reason is both Problems 1 and 2 provide a challenging problem for the researchers, since they are open problems. Swita et al. [9] proved Problem 2 for $a=7$ or $a=$ $4 x-1$ for any integer $x$. MacDougall and Wallis [13] proved Problem 2 for $m=n=1$ that a graph $B[(a, 1),(b, 1), 2]$ is a super edge-magic total labeling. Let $l=\min (a, b)-3$. Notice that $l$ is a chord of cycle $C_{(a+b-2)}$. Thus, $l$ is a chord of graph $B[(a, 1),(b, 1), 2]$. Using Kotzig array, Singgih $[14,15]$ proposed a new method to construct an edge-magic total labeling (super edge-magic) of graph cycle $C_{(a+b-2)(2 r+1)^{h}}$ with $\left[(2 r+1)^{h}\right] z$ chords, each of length $l=(a, b)-3$, from an edge-magic total labeling (super edge-magic) of graph $B[(a, 1),(b, 1), 2]$, where $h$ and $z$ are the positive integers.

Berkman, Parnas and Roditty [16], Enomoto et al. [3], Kotzig and Rosa [2], and Godbold and Slater [17] are among others authors that discuss Problem 1 for $m=1$. For $m \geq 2$, Problem 1 is an open problem; however, some authors provided a partial solution. Figueroa-Centeno, Ichishima, and Muntaner-Batle [18] proved that $B[(4, m), 2]$ is an edgemagic total. Furthermore, they proved that $\mathrm{B}[(4, m), 2]$ is not super edge-magic total for $m \equiv 1,3,7 \bmod (8))$ and $m=4$, but $\mathrm{B}[(4, m), 2]$ is super edge-magic total for $m=2,5,6,8,10,11$. Moreover, they made the following conjecture.

Cycle book conjecture [18]: the graph $\mathrm{B}[(4, m), 2]$ is super edge-magic total if and only if $m$ is even or $m \equiv 5 \bmod (8)$.

Gallian [7] reported that Yuansheng et al. [19] proved this conjecture for $m$ is even in Ars Combinatoria, 93 (2009) 431-438. A study [20] contains the abstract of Yuansheng et al. [19] and claims that Yuansheng et al. proved the cycle book conjecture is true for $m$ is even. The study [19] is the same as that of Gallian [7]. We trace this reference, and we find that this reference is neither in the table of contents of Ars Combinatoria, 93 (2009), nor in the table of contents Ars Combinatoria from 1995 up to 1999. Hence, we assume that the article of Yuansheng et al. is unpublished. Therefore, it is reasonable to publish this article. Thus, this study proves the cycle book conjecture for $m \geq 36$ and $m=0 \bmod (2)$. The solution of cycle book conjecture is available from the author for $12 \leq m \leq 34$ and $m=0 \bmod (2)$.

\section{Preliminary Notes}

In this section, we provide some previous results on super edge-magic total labeling of a graph. Figuero-Centeno, Ichisma, and Mutaner-Batle [18] proved some necessary conditions for super edge-magic total labeling of a graph. We need them to prove the main results of this study. First, we define some notations in the following definition.

Definition 1. Let $G$ be a graph $B[(4, m), 2], X=\left\{u_{m+2}\right\}$, $Y=\left\{v_{m+2}\right\}, \quad Z=\left\{u_{1}, u_{2}, \ldots, u_{m / 2+1}, u_{m / 2+3}, \ldots, u_{m+1}\right\}$, and $W=\left\{v_{1}, v_{2}, \ldots, v_{m / 2+1}, v_{m / 2+3}, \ldots, v_{m+1}\right\}$. We define the vertex set $V(G)=X \cup Y \cup Z \cup W$ and the edge set $E(G)=$ $\{(x, y): x \in X, y \in Y\} \cup\{(x, y): x \in Z, y \in W\} \cup\{(x, y):$ $x \in X, y \in Z\} \cup\{(x, y): x \in Y, y \in W\}$.

The element of $X \cup Y$ and the edge $\left(u_{m / 2+2}, v_{m / 2+2}\right)$ are called the common vertices and common edge of the $m$ copies of $C_{a}$, respectively.

The graph $\mathrm{B}[(4, \mathrm{~m}), 2]$ in Definition 1 is shown in Figure 1 and the graph $B[(a, m),(b, n), 2]$ is shown in Figure 2 .

Theorem 1 (see [18]). Let $G$ be a graph, such that $|(V G)|=p$ and $|E(G)|=q$. Then, $G$ is super edge-magic total if and only if there exists a bijective function $f: V(G) \longrightarrow\{1,2, \ldots, p\}$, such that the set $S=\{f(w)+f(z): f$ or any edge $w z \in E$ $(G)\}$ consists of $q$ consecutive integers. In such a case, $f$ extends to a super edge-magic total labeling of $G$ with magic constant $k=p+q+s$, where $s=\min (S)$ and $S=\{k-(p+$ $1), k-(p+2), \ldots, k-(p+q)\}$.

Theorem 2 (see [18]). Let $G$ be a graph, such that $|(V G)|=p$ and $|E(G)|=q$ and $f$ be a super edge-magic total labeling of G. Let $S=\{f(w)+f(z): w z \in E(G)\}$ and $s=\min (S)$. Then, $\sum_{v \in V(G)} f(v) \operatorname{deg}(v)=q s+(q-1) q / 2$. In particular, $2 \sum_{v \in V(G)} f(v) \operatorname{deg}(v) \equiv \bmod (q)$.

Theorem 3 (see [18]). Let $G$ be a graph $B[(4, m), 2]$, such that $S=\{f(w)+f(z): w z \in E(G)\}$ and $s=\min (S)$. If $G$ is super edge-magic total labeling, then $s=m / 2+3$.

The following theorem is derived from the proof of Theorem 3 in [3]. For self-contained of this article, we rewrite the proof again.

Theorem 4 (see [18]). Let $G$ be a graph $B[(4, m), 2]$ in Definition 1 and let $\left(u_{m / 2+2}, v_{m / 2+2}\right)$ be the common edges of all cycles $C_{4}$ in $G$. If $G$ is super edge-magic total labeling, then $f\left(u_{m / 2+2}\right)+f\left(v_{m / 2+2}\right)=6 m s+m^{2}+2 s-17 m-12 / 2 m-2$.

Proof. Let $G$ be a graph $B[(4, m), 2]$ in Definition 1 . Let $|V(G)|=p,|E(G)|=q$, and $t=m / 2+2$. We first notice that $p=2 m+2$ and $q=3 m+1$. Moreover, $\operatorname{deg}\left(u_{t}\right)=\operatorname{deg}\left(v_{t}\right)=$ $m+1, \operatorname{deg}\left(u_{1}\right)=\operatorname{deg}\left(v_{1}\right)=\cdots=\operatorname{deg}\left(u_{t-1}\right)=\operatorname{deg}\left(v_{t-1}\right)=$ $\operatorname{deg}\left(u_{t+1}\right)=\operatorname{deg}\left(v_{t+1}\right)=\ldots, \operatorname{deg}\left(u_{m+1}\right)=\operatorname{deg}\left(v_{m+1}\right)=2$.

Let $A=X \cup \mathrm{Y}$ and $B=Z \cup \mathrm{W}$. By Theorem 2, we have $(m+1) \sum_{w \in A} f(w)+2 \sum_{w \in B} f(w)=q s+(q-1) q / 2 \quad$ or $(m-1) \sum_{w \in A} f(w)+2 \sum_{w \in B} f(w)=q s+(q-1) q / 2$. The last equality reduces to $\sum_{w \in A} f(w)+2 \sum_{i=1}^{2 m+2} i=q s+(q-1) q / 2$, 


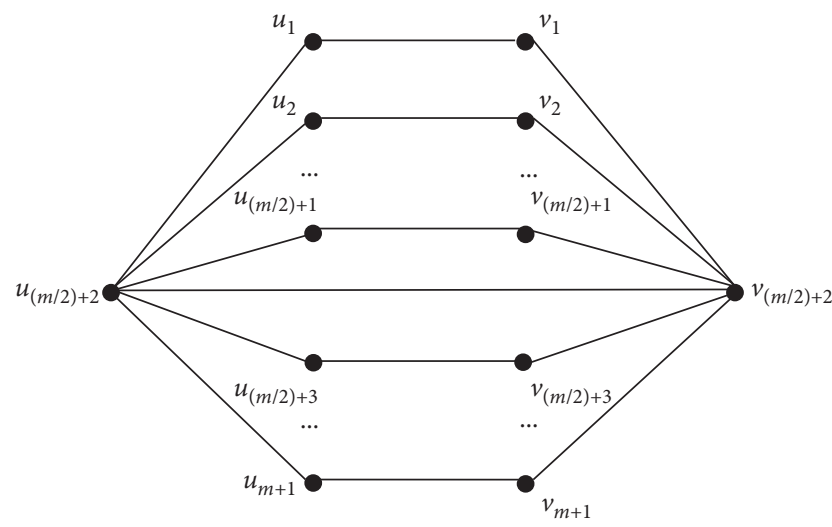

Figure 1: Graph $\mathbf{B}[(4, \mathbf{m}), 2]$.

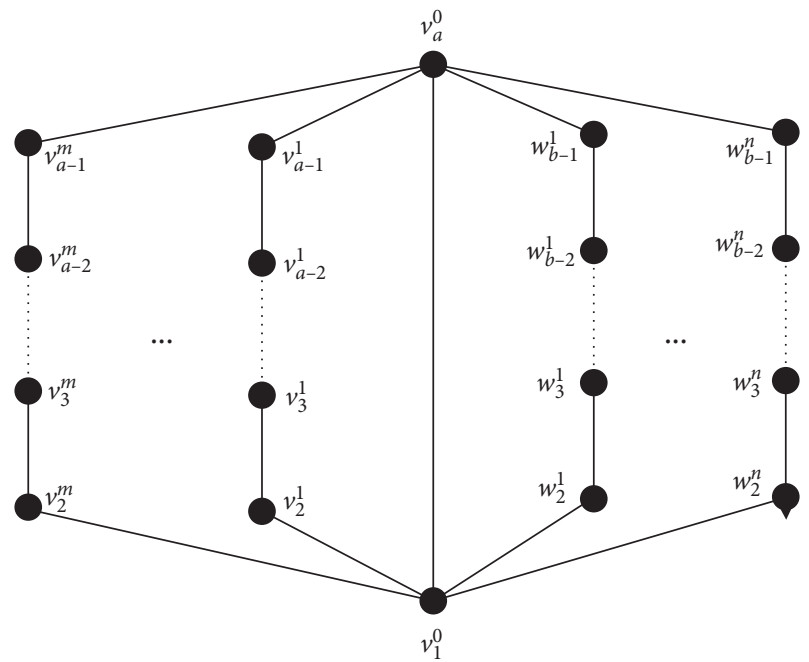

Figure 2: Graph B [(a, m), (b, n), 2].

since $f(w), f(z) \in\{1,2, \ldots,(2 m+2)\}$, and $f(w) \neq f(z)$. Thus, $(m-1) \sum_{w \in A} f(w)+(2 m+2)(2 m+3)=q s+(q-1)$ $q / 2$. We substitute $q=3 m+1$ to the last equation, and we have the following equation.

$$
f\left(u_{t}\right)+f\left(v_{t}\right)=\frac{6 m s+m^{2}+2 s-17 m-12}{2 m-2} .
$$

By the equation (1) and $s=m / 2+3$ in Theorem 3, we conclude that $f\left(u_{t}\right)+f\left(v_{t}\right)=2 m+3$. Hence, the theorem.

\section{Proof of Cycle Book Conjecture for $\mathbf{m}$ Is Even}

In this section, we prove that the cycle book conjecture is true if $m$ is even and $m \geq 36$.

Theorem 5. Let $G$ be the graph $B[(4, m), 2]$ in Definition 1 with $|V(G)|=p,|E(G)|=q, m$ is an even integer, $m \geq 36$., and let $f$ be an edge-magic total labeling of $G$. Let $S=\{f(w)+f(s): f \quad$ or any edge $w z \in E(G)]$ and $s=\min (S)$. Then, $G$ is a super edge-magic total if and only if

(i) $\left.f\left(u_{m / 2+2}\right)+f\left(v_{m / 2+2}\right)\right)=6 m s+m^{2}+2 s-17 m-12$ $/ 2 m-2$ (ii) $s=m / 2+3$

(iii) $S$ is a set of $q$ consecutive integers

(iv) $k=p+q+s$

Proof. Let $G$ be the graph $B[(4, m), 2]$ with $|V(G)|=p,|E(G)|=q$, and let $G$ be a super edge-magic total. Note that $p=2 m+2$ and $q=3 m+1$. Let $f$ be an edge-magic total labeling of $G$. If $f$ is a super edge-magic total labeling of $G$, then the conditions (i) and (ii) follow from Theorems 4 and 3, respectively, and the conditions (iii) and (iv) follow from Theorem 1.

Let $f$ satisfies the conditions (i), (ii), (iii), and (iv). By (i) and (ii), we conclude that

$$
f\left(u_{m / 2+2}\right)+f\left(v_{m / 2+2}\right)=2 m+3 .
$$

The pair $(m / 2+2,3 m / 2+1)$ is one of the solutions of equation (2) with $f\left(u_{m / 2+2}\right)=m / 2+2$ and $f\left(v_{m / 2+2}\right)$ $=3 \mathrm{~m} / 2+1$. By this solution, we define the bijection $f_{1}(x)$, such that $f_{1}\left(u_{m / 2+2}\right)=f\left(u_{m / 2+2}\right)=m / 2+2$ and $f_{1}\left(v_{m / 2+2}\right)$ $=f\left(v_{m / 2+2}\right)=3 m / 2+1$ as follows.

$$
\begin{aligned}
& f_{1}\left(u_{i}\right)=\frac{m}{2}+2, \quad i=\frac{m}{2}+2, \\
& f_{1}\left(v_{i}\right)=\frac{3 m}{2}+1, \quad i=\frac{m}{2}+2, \\
& f_{1}\left(u_{i}\right)=i, \quad i=1,2, \ldots, m+1, \\
& f_{1}\left(v_{i}\right)=\frac{3 m}{2}+3, \quad i=1, \\
& f_{1}\left(v_{i}\right)=m+2, \quad i=2, \\
& f_{1}\left(v_{i}\right)=\frac{3 m}{2}+2, \quad i=3, \\
& f_{1}\left(v_{i}\right)=2 m+1, \quad i=m+1 .
\end{aligned}
$$

Case $1: m \equiv 0 \bmod (4)$

We define

$$
\begin{aligned}
& f_{1}\left(v_{i}\right)=\frac{3 m}{2}+3-\left(\frac{i+1}{2}\right), \\
& \quad i=m-1, m-3, \ldots, \frac{m}{2}+5, \frac{m}{2}+3, \\
& f_{1}\left(v_{i}\right)=\frac{5 m+8}{4}, \quad i=m, \\
& f_{1}\left(v_{i}\right)=\frac{3 m}{2}-\left(\frac{i-6}{2}\right), \quad i=\frac{m}{2}, \frac{m}{2}-2, \ldots, 8,6 . \\
& f_{1}\left(v_{i}\right)=2 m+3-\frac{i}{2}, \quad i=m-2, m-4, \ldots, \frac{m}{2}+6, \frac{m}{2}+4,
\end{aligned}
$$


$f_{1}\left(v_{i}\right)=\frac{7 m+12}{4}, \quad i=\frac{m}{2}+1$.

Case 1.1: $m \equiv 0 \bmod (12)$

We define

$f_{1}\left(v_{i}\right)=2 m+\left(\frac{3-i}{2}\right), \quad i=5,11,17, \ldots, \frac{m}{2}-7, \frac{m}{2}-1$,

$f_{1}\left(v_{i}\right)=2 m-\left(\frac{i-3}{2}\right), \quad i=7,13,19, \ldots, \frac{m}{2}-11, \frac{m}{2}-5$,

$f_{1}\left(v_{i}\right)=2 m-\left(\frac{i-9}{2}\right), \quad i=9,15,21, \ldots, \frac{m}{2}-9, \frac{m}{2}-3$,

$f_{1}\left(v_{i}\right)=2 m+2, \quad i=4$.

Next, we will show that $S$ is a set of $q$ consecutive integers with $q=3 m+1$. Recall that $X=\left\{u_{m / 2+2}\right\}$ and $Y=\left\{v_{m / 2+2}\right\}$.

Let $Z_{1}^{1}=\left\{u_{1}, u_{2}, \ldots, u_{m / 2+2}+1\right\}$ and $S_{1}^{1}=\left\{f_{1}(x)+f_{1}\right.$ $\left.(y): x \in X, y \in Z_{1}\right\}$. Let $x \in X$. By equations (3) and (5), we conclude that $f_{1}(x)+f_{1}\left(u_{i}\right)=m / 2+2+i$, $i=1,2, \ldots, m / 2+1$. Hence, $S_{1}^{1}=\{m / 2+3, m / 2+4$, $\ldots, m+2, m+3\}$.

Let $Z_{2}^{1}=\left\{u_{2}\right\}, W_{1}^{1}=\left\{v_{2}\right\} \quad$ and $\quad S_{2}^{1}=\left\{f_{1}(x)+f_{1}\right.$ $\left.(y): x \in Z_{2}, y \in W_{1}\right\}$. Let $x \in Z_{2}$ and $y \in W_{1}$. By equations (5) and (7), we conclude that $f_{1}(x)+$ $f_{1}(y)=2+m+2=m+4$. Hence, $S_{2}^{1}=\{m+4\}$.

Let $=Z_{3}^{1}=\left\{u_{m / 2+3}, u_{m / 2+4}, \ldots, u_{m}, u_{m+1}\right\}, Z_{4}^{1}=X$, and $S_{3}^{1}=\left\{f_{1}(x)+f_{1}(y): x \in Z_{3}^{1}, y \in Z_{4}^{1}\right\}$. Let $x \in Z_{4}^{1}$ and $u_{i} \in Z_{3}^{1}$. By equations (3) and (5), we conclude that $f_{1}(x)+f_{1}\left(u_{i}\right)=m / 2+2+i, i=m / 2+3, m / 2+4$, $\ldots, m+1$. Hence, $S_{3}^{1}=\{m+5, m+6, \ldots, 3 m / 2,3 m / 2+$ $2,3 m / 2+3\}$.

Let $Z_{5}^{1}=\left\{u_{1}, u_{3}\right\}, W_{2}^{1}=\left\{v_{1}, v_{3}\right\}$, and $S_{4}^{1}=\left\{f_{1}\left(u_{i}\right)+f_{1}\right.$ $\left.\left(v_{i}\right): u_{i} \in Z_{5}, v_{i} \in W_{2}\right\}$. By equations (5) and (6), we conclude that $f_{1}\left(u_{1}\right)+f_{1}\left(v_{1}\right)=1+3 m / 2+3=3 m / 2$ +4 . By equations (5) and (8), we conclude that $f_{1}\left(u_{3}\right)+f_{1}\left(v_{3}\right)=3+3 m / 2+2=3 m / 2+5$. Hence, $S_{4}^{1}=\{3 m / 2+4,3 m / 2+5\}$.

Let $Z_{6}^{1}=\left\{u_{6}, u_{8}, \ldots, u_{m / 2-2}, u_{m / 2}\right\}, W_{3}^{1}=\left\{v_{6}, v_{8}, \ldots\right.$, $\left.v_{m / 2-2}, v_{m / 2}\right\}$, and $S_{5}^{1}=\left\{f_{1}\left(u_{i}\right)+f_{1}\left(v_{i}\right): u_{i} \in Z_{6}^{1}, v_{i} \in\right.$ $\left.W_{3}^{1}, i=6,8, \ldots, m / 2-2, m / 2\right\}$. By equations (5) and (12), we conclude that $f_{1}\left(u_{i}\right)+f_{1}\left(v_{i}\right)=i+3 m / 2-(i-$ $6 / 2), i=6,8, \ldots, m / 2$. Hence, $S_{5}^{1}=\{3 m / 2+6,3 m / 2+$ $7,3 m / 2+8, \ldots, 7 m / 4+2,7 m / 4+3\}$.

Let $Z_{7}^{1}=\left\{u_{m / 2+3}, u_{m / 2+5}, \ldots, u_{m-3}, u_{m-1}\right\}, W_{4}^{1}=\left\{v_{m / 2+3}\right.$, $\left.v_{m / 2+5}, \ldots, u_{m-3}, u_{m-1}\right\}$, and $S_{6}^{1}=\left\{f_{1}\left(u_{i}\right)+f_{1}\left(v_{i}\right)\right.$ : $u_{i} \in Z_{7}^{1}, \quad v_{i} \in W_{4}^{1}, i=m / 2+3, m / 2+5, \ldots, m-3$, $m-1\}$. By equations (5) and (10), we conclude that $f_{1}\left(u_{i}\right)+f_{1}\left(v_{i}\right)=i+3 m / 2+3-(i+1 / 2), i=m / 2+3$, $m / 2+5, \ldots, m-3, m-1$. Hence, $S_{6}^{1}=\{7 m / 4+4,7 m /$ $4+5, \ldots, 2 m+1,2 m+2\}$.

Let $\quad Z_{8}^{1}=X, W_{5}^{1}=Y \quad$ and $\quad S_{7}^{1}=\left\{f_{1}(x)+f_{1}\right.$ $\left.(y): x \in Z_{8}, y \in W_{5}\right\}$. By equations (3) and (4), we conclude that $f_{1}\left(u_{m / 2+2}\right)+f_{1}\left(v_{m / 2+2}\right)=m / 2+2+$ $3 m / 2+1=2 m+3$. Hence, $S_{7}^{1}=\{2 m+3\}$.

Let $Z_{9}^{1}=\left\{u_{i}: i \equiv 5(\bmod 6)\right\}=\left\{u_{5}, u_{11}, \ldots, u_{m / 2-7}\right.$, $\left.u_{m / 2-1}\right\}, W_{6}^{1}=\left\{v_{i}: i \equiv 5(\bmod 6)\right\}=\left\{v_{5}, v_{11}, \ldots, v_{m / 2-7}\right.$, $\left.v_{m / 2-1}\right\}$, and $S_{8}^{1}=\left\{f_{1}\left(u_{i}\right)+f_{1}\left(v_{i}\right): u_{i} \in Z_{9}^{1}, v_{i} \in W_{6}^{1}\right\}$. By equations (5) and (15), we conclude that $f_{1}\left(u_{i}\right)+$ $f_{1}\left(v_{i}\right)=i+2 m+(3-i / 2), i=5,11,17, \ldots, m / 2-7$, $m / 2-1$. Hence, $S_{8}^{1}=\{2 m+4,2 m+7, \ldots, 9 m / 4-2$, $9 m / 4+1\}$.

Let $Z_{10}^{1}=\left\{u_{i}: i \equiv 1(\bmod 6)\right\}=\left\{u_{7}, u_{13}, \ldots, u_{m / 2-11}\right.$, $\left.u_{m / 2-5}\right\}, W_{7}^{1}=\left\{v_{i}: i \equiv 1(\bmod 6)\right\}=\left\{v_{7}, v_{13}, \ldots, v_{m / 2-11}\right.$, $\left.v_{m / 2-5}\right\}$, and $S_{9}^{1}=\left\{f_{1}\left(u_{i}\right)+f_{1}\left(v_{i}\right): u_{i} \in Z_{10}^{1}, v_{i} \in W_{7}\right\}$. By equations (5) and (16), we conclude that $f_{1}\left(u_{i}\right)+$ $f_{1}\left(v_{i}\right)=i+2 m-(I-3 / 2), i=7,13,19, \ldots, m / 2-11$, $m / 2-5$. Hence, $S_{9}^{1}=\{2 m+5,2 m+8,2 m+11, \ldots$, $9 m / 4-1\}$.

Let $Z_{11}^{1}=\left\{u_{4}\right\}, W_{8}^{1}=\left\{v_{4}\right\}$, and $S_{10}^{1}=\left\{f_{1}(x)+f_{1}(y)\right.$ : $\left.x \in Z_{11}^{1}, y \in W_{8}\right\}$. By equations (5) and (18), we conclude that $f_{1}\left(u_{4}\right)+f_{1}\left(v_{4}\right)=2 m+6$. Hence, $S_{10}^{1}=\{2 m+6\}$.

Let $Z_{12}^{1}=\left\{u_{i}: i \equiv 3=\{(\bmod 6)\}=\left\{u_{9}, u_{15}, \ldots, u_{m / 2-11}\right.\right.$, $\left.u_{m / 2-9}, u_{m / 2-3}\right\}, \quad W_{9}^{1}=\left\{v_{i}: i \equiv 3(\bmod 6)\right\}=\left\{v_{9}, v_{15}\right.$, $\left.\ldots, v_{m / 2-15}, v_{m / 2-9}, \quad u_{m / 2-3}\right\}, \quad$ and $S_{11}^{1}=\left\{f_{1}\left(u_{i}\right)+f\right.$ $\left.\left(v_{i}\right): u_{i} \in Z_{12}^{1}, v_{i} \in W_{9}^{1}\right\}$. By equations (5) and (17), we conclude that $f_{1}\left(u_{i}\right)+f_{1}\left(v_{i}\right)=i+2 m-(I-9 / 2), i=$ $9,15,21, \ldots, m / 2-9, m / 2-3$. Hence, $S_{11}^{1}=\{2 m+$ $9,2 m+12,2 m+15, \ldots, 9 m / 4-3,9 m / 4,9 m / 4+3\}$.

Let $Z_{13}^{1}=\left\{u_{m}\right\}, W_{10}^{1}=\left\{v_{m}\right\}$, and $S_{12}^{1}=\left\{f_{1}(x)+f_{1}(y)\right.$ : $\left.x \in Z_{13}^{1}, y \in W_{10}^{1}\right\}$. By equations (5) and (11), we conclude that $f_{1}\left(u_{m}\right)+f_{1}\left(v_{m}\right)=m+5 m / 4+$ $2=9 m / 2+2$. Hence, $S_{12}^{1}=\{9 m / 4+2\}$.

Let $Z_{14}^{1}=\left\{u_{m / 2+1}\right\}, W_{11}^{1}=\left\{v_{m / 2+1}\right\}$, and $S_{13}^{1}=\left\{f_{1}(x)+\right.$ $\left.f_{1}(y): x \in Z_{14}^{1}, y \in W_{11}^{1}\right\}$. By equations (5) and (14), we conclude that $f_{1}\left(u_{m / 2+1}\right)+f_{1}\left(v_{m / 2+1}\right)=m / 2+1+$ $7 m / 4+3=9 m / 4+4$. Hence, $S_{13}^{1}=\{9 m / 4+4\}$.

Let $Z_{15}^{1}=\left\{u_{m / 2+4}, u_{m / 2+6}, \ldots, u_{m-4}, u_{m-2}\right\}, \quad W_{12}^{1}=\left\{v_{m /}\right.$ $\left.2+4, v_{m / 2+6}, \ldots, v_{m-4}, v_{m-2}\right\}$, and $S_{14}^{1}=\left\{f_{1}\left(u_{i}\right)+\right.$ $\left.f_{1}\left(v_{i}\right): u_{i} \in Z_{15}^{1}, v_{i} \in W_{12}^{1}\right\}$. By equations (5) and (13), we conclude that $f_{1}\left(u_{i}\right)+f_{1}\left(v_{i}\right)=i+2 m+3-i / 2, i=$ $m / 2+4, m / 2+6, \ldots, m-4, m-2$. Hence, $S_{14}^{1}=\{9 m /$ $4+5,9 m / 4+6,9 m / 4+7, \ldots, 5 m / 2, \quad 5 m / 2+1, \quad 5 m /$ $2+2\}$.

Let $W_{13}^{1}=Y=\left\{v_{m / 2+2}\right\}, W_{14}^{1}=\left\{v_{2}\right\}$, and $S_{15}^{1}=\left\{f_{1}\right.$ $\left.(x)+f_{1}(y): x \in W_{13}^{1}, y \in W_{14}^{1}\right\}$. By equations (4) and (7), we conclude that $f_{1}\left(v_{m / 2+2}\right)+f_{1}\left(v_{2}\right)=3 m / 2+$ $1+m+2=5 m / 2+3$. Hence, $S_{15}^{1}=\{5 m / 2+3\}$.

Let $W_{15}^{1}=Y=\left\{v_{m / 2+2}\right\}, W_{16}^{1}=\left\{v_{m-1}, v_{m-3}, \ldots, v_{m / 2+5}\right.$, $\left.v_{m / 2+3}\right\}$, and $S_{16}^{1}=\left\{f_{1}(x)+f_{1}(y): x \in W_{15}^{1}, y \in W_{16}^{1}\right\}$. By equations (4) and (10), we conclude that $f_{1}\left(v_{m / 2+2}\right)+f_{1}\left(v_{i}\right)=3 m / 2+1+3 m / 2+3-(i+1 / 2)$, 
$i=m-1, m-3, m-5, \ldots, m / 2+5, m / 2+3$. Hence, $S_{16}^{1}=\{5 m / 2+4,5 m / 2+5, \ldots, 11 m / 4+1,11 m / 4+2\}$.

Let $W_{17}^{1}=Y=\left\{v_{m / 2+2}\right\}, W_{18}^{1}=\left\{v_{m}\right\}$, and $S_{17}^{1}=\left\{f_{1}(x)+\right.$ $\left.f_{1}(y): x \in W_{17}^{1}, y \in W_{18}^{1}\right\}$. By equations (4) and (11), we conclude that $f_{1}\left(v_{m / 2+2}\right)+f_{1}\left(v_{m}\right)=3 m / 2+$ $1+5 m / 4+2=11 m / 4+3$. Hence, $S_{17}^{1}=\{11 m / 4+3\}$.

Let $\quad W_{19}^{1}=Y=\left\{v_{m / 2+2}\right\}, \quad W_{20}^{1}=\left\{v_{m / 2}, v_{m / 2-2}, \ldots\right.$, $\left.v_{8}, v_{6}\right\}$, and $S_{16}^{1}=\left\{f_{1}(x)+f_{1}(y): x \in W_{19}, y \in W_{20}^{1}\right\}$. By equations (4) and (12), we conclude that $f_{1}\left(v_{m / 2+2}\right)+f_{1}\left(v_{i}\right)=3 m / 2+1+3 m / 2-(i-6 / 2), i=$ $m / 2, m / 2-2, m / 2-4, \ldots, 8,6$. Hence, $S_{18}^{1}=\{11 m /$ $4+4,11 m / 4+5, \ldots, 3 m, 3 m+1\}$.

Let $Z_{16}^{1}=\left\{u_{m+1}\right\}, W_{21}^{1}=\left\{v_{m+1}\right\}$, and $S_{19}^{1}=\left\{f_{1}(x)+\right.$ $\left.f_{1}(y): x \in Z_{16}^{1}, y \in W_{21}^{1}\right\}$. By equations (5) and (9), we conclude that $f_{1}\left(u_{m+1}\right)+f_{1}\left(v_{m+1}\right)=m+1+2 m+$ $1=3 m+2$. Hence, $S_{19}^{1}=\{3 m+2$,$\} .$

Let $W_{22}^{1}=Y=\left\{v_{m / 2+2}\right\}, W_{23}^{1}=\left\{v_{3}, v_{1}\right\}$, and $S_{20}^{1}=\left\{f_{1}\right.$ $\left.(x)+f_{1}(y): x \in W_{22}^{1}, y \in W_{23}^{1}\right\}$. By equations (4) and (8), we conclude that $f_{1}\left(v_{m / 2+2}\right)+f_{1}\left(v_{3}\right)=3 m / 2$ $+1+3 m / 2+2=3 m+3$. By equations (4) and (6), we conclude that $f_{1}\left(v_{m / 2+2}\right)+f_{1}\left(v_{1}\right)=3 m / 2+1+3 m / 2$ $+3=3 m+4$. Hence, $S_{20}^{1}=\{3 m+3,3 m+4\}$.

Let $\quad W_{24}^{1}=Y=\left\{v_{m / 2+2}\right\}, \quad W_{25}^{1}=\left\{v_{m-2}, v_{m-4}, \ldots\right.$, $\left.v_{m / 2+6}, v_{m / 2+4}\right\}$, and $S_{21}^{1}=\left\{f_{1}(x)+f_{1}(y): x \in W_{24}^{1}\right.$, $\left.y \in W_{25}^{1}\right\}$. By equations (4) and (13), we conclude that $f_{1}\left(v_{m / 2+2}\right)+f_{1}\left(v_{i}\right)=3 m / 2+1+2 m+3-i / 2, i=m-$ $2, m-4, \ldots . ., m / 2+6, m / 2+4$. Hence, $S_{21}^{1}=\{3 m+$ $5,3 m+6, \ldots, 13 m / 4+1,13 m / 4+2\}$.

Let $\quad W_{26}^{1}=Y=\left\{v_{m / 2+2}\right\}, \quad W_{27}^{1}=\left\{v_{m / 2-1}, v_{m / 2-7}, \ldots\right.$, $\left.v_{11}, v_{5}\right\}$, and $S_{22}^{1}=\left\{f_{1}(x)+f_{1}(y): x \in W_{26}^{1}, y \in W_{27}^{1}\right\}$. By equations (4) and (15), we conclude that $f_{1}$ $\left(v_{m / 2+2}\right)+f_{1}\left(v_{i}\right)=3 m / 2+1+2 m+(3-i) / 2, i=m / 2$ $-1, m / 2-7, \ldots, 11,5$. Hence, $S_{22}^{1}=\{13 m / 4+3,13 m /$ $4+6, \ldots, 7 m / 2-3,7 m / 2\}$.

Let $W_{28}^{1}=Y=\left\{v_{m / 2+2}\right\}, \quad W_{29}^{1}=\left\{v_{m / 2+1}\right\}, \quad$ and $S_{23}^{1}=\left\{f_{1}(x)+f_{1}(y): x \in W_{28}^{1}, y \in W_{29}^{1}\right\}$. By equations (4) and (14), we conclude that $f_{1}\left(v_{m / 2+2}\right)+$ $f_{1}\left(v_{m / 2+1}\right)=3 m / 2+1+7 m / 4+3=13 m / 4+4$. Hence, $S_{23}^{1}=\{13 m / 4+4\}$.

Let $\quad W_{30}^{1}=Y=\left\{v_{m / 2+2}\right\}, W_{31}^{1}=\left\{v_{m / 2-5}, v_{m / 2-11}, \ldots\right.$, $\left.v_{13}, v_{7}\right\}$, and $S_{24}^{1}=\left\{f_{1}(x)+f_{1}(y): x \in W_{30}^{1}, y \in W_{31}^{1}\right\}$. By equations (4) and (16), we conclude that $f_{1}$ $\left(v_{m / 2+2}\right)+f_{1}\left(v_{i}\right)=3 m / 2+1+2 m-(i-3) / 2, i=m / 2$ $-5, m / 2-11, \ldots, 13,7$. Hence, $S_{24}^{1}=\{13 m / 4+5,13 m$ $14+8, \ldots, 7 m / 2-4,7 m / 2-1\}$.

Let $W_{32}^{1}=Y=\left\{v_{m / 2+2}\right\}, W_{33}^{1}=\left\{v_{m / 2-3}, v_{m / 2-9}, \ldots, v_{15}\right.$, $\left.v_{9}\right\}$, and $S_{25}^{1}=\left\{f_{1}(x)+f_{1}(y): x \in W_{32}^{1}, y \in W_{33}^{1}\right\}$. By equations (4) and (17), we conclude that $f_{1}\left(v_{m / 2+2}\right)+$ $f_{1}\left(v_{i}\right)=3 m / 2+1+2 m-(i-9) / 2, i=m / 2-3, m / 2$ $-9, \ldots, 15,9$. Hence, $S_{25}^{1}=\{13 m / 4+7,13 m / 4$ $+10, \ldots, 7 m / 2-2,7 m / 2+1\}$.

Let $W_{34}^{1}=Y=\left\{v_{m / 2+2}\right\}, W_{35}^{1}=\left\{v_{m+1}\right\}$, and $S_{26}^{1}=\left\{f_{1}\right.$ $\left.(x)+f_{1}(y): x \in W_{34}^{1}, y \in W_{35}^{1}\right\}$. By equations (4) and (9), we conclude that $f_{1}\left(v_{m / 2+2}\right)+f_{1}\left(v_{m+1}\right)=3 m / 2+$ $1+2 m+1=7 m / 2+2$. Hence, $S_{26}^{1}=\{7 m / 2+2\}$.
Let $W_{36}^{1}=Y=\left\{v_{m / 2+2}\right\}, W_{37}^{1}=\left\{v_{4}\right\}$, and $S_{27}^{1}=\left\{f_{1}(x)+\right.$ $\left.f_{1}(y): x \in W_{36}^{1}, y \in W_{37}^{1}\right\}$. By equations (4) and (18), we conclude that $f_{1}\left(v_{m / 2+2}\right)+f_{1}\left(v_{4}\right)=3 m / 2+$ $1+2 m+2=7 m / 2+3$. Hence, $S_{27}^{1}=\{7 m / 2+3\}$.

Next, we will show that $S_{8}^{1} \cup S_{9}^{1} \cup S_{10}^{1} \cup S_{11}^{1} \cup S_{12}^{1}$ consists of $3 m / 12$ consecutive integers. Simple counting shows that $\left|S_{8}^{1}\right|=m / 12$, and $\left|S_{9}^{1}\right|=\left|S_{11}^{1}\right|=m / 12-1,\left|S_{10}^{1}\right|=$ $\left|S_{12}^{1}\right|=1$. We arrange the term of $S_{8}^{1} \cup S_{9}^{1} \cup S_{10}^{1}$ $\cup S_{11}^{1} \cup S_{12}^{1}$ in Table 1 .

We observe from Table 1 that $S_{8}^{1} \cup S_{9}^{1} \cup S_{10}^{1} \cup S_{11}^{1} \cup S_{12}^{1}=$ $\{2 m+4,2 m+5,2 m+6, \ldots, 9 m / 4+1,9 m / 4+2,9 m / 4$ $+3\}$ consists of $3 m / 12$ consecutive integers.

In addition, we will show that $S_{22}^{1} \cup\left(S_{25}^{1} \cup S_{23}\right)^{1} \cup S_{24}^{1}$ consists of $3 m / 12-1$ consecutive integers. Simple counting shows that $\left|S_{22}^{1}\right|=m / 12, \quad\left|S_{24}^{1}\right|=\left|S_{25}^{1}\right|=$ $m / 13-1$, and $\left|S_{23}\right|=1$. By these information, we arrange the terms of $S_{22}^{1} \cup\left(S_{25}^{1} \cup S_{23}\right)^{1} \cup S_{24}^{1}$ in Table 2 .

We observe from Table 2 that $S_{22}^{1} \cup\left(S_{25}^{1} \cup S_{23}\right) \cup S_{24}^{1}=$ $\{13 m / 4+3,13 m / 4+4,13 m / 4+5, \ldots, 7 m / 2-1,7 m / 2$, $7 m / 2+1\}$ consists of $3 m / 12-1$ consecutive integers. Let $S=S_{1}^{1} \cup S_{2}^{1} \cup \cdots \cup S_{26}^{1} \cup S_{27}^{1}$. We will show that $S$ consists of $q$ consecutive integers with $q=3 m+1$.

Let

$S_{1}^{1}=\{(m / 2)+3,(m / 2)+4, \ldots, m+2, m+3\}=T_{1}^{1}$,

$S_{2}^{1}=\{m+4\}=T_{2}^{1}$,

$S_{3}^{1}=\{m+5, m+6, \ldots,(3 m / 2)+2,(3 m / 2)+3\}=T_{3}^{1}$,

$S_{4}^{1}=\{(3 m / 2)+4,(3 m / 2)+5\}=T_{4}^{1}$,

$S_{5}^{1}=\{(3 m / 2)+6,(3 m / 2)+7, \ldots,(7 m / 4)+2$,

$(7 m /$

4) +3$\}=T_{5}^{1}$,

$S_{6}^{1}=\{(7 m / 4)+4,(7 m / 4)+5, \ldots, 2 m+1,2 m+2\}=T_{6}^{1}$,

$S_{7}^{1}=\{2 m+3\}=T_{7}^{1}$,

$S_{8}^{1} \cup S_{9}^{1} \cup S_{10}^{1} \cup S_{11}^{1} \cup S_{12}^{1}=2 m+4,2 m+5,2 m+6, \ldots$,

$(9 m / 4)+1,(9 m / 4)+2,(9 m / 4)+3=T_{8}^{1}$

$S_{13}^{1}=\{(9 m / 4)+4\}=T_{9}^{1}$,

$S_{14}^{1}=\{(9 m / 4)+5,(9 m / 4)+6,(9 m / 4)+7, \ldots,(5 m /$

$2),(5 m / 2)+1,(5 m / 2)+2\}=T_{10}^{1}$,

$S_{15}^{1}=\{(5 m / 2)+3\}=T_{11}^{1}$,

$S_{16}^{1}=\{(5 m / 2)+4,(5 m / 2)+5, \ldots,(11 m / 4)+1,(11 m /$

$4)+2\}=T_{12}^{1}$,

$S_{17}^{1}=\{(11 m / 4)+3\}=T_{13}^{1}$,

$S_{18}^{1}=\{(11 m / 4)+4,(11 m / 4)+5, \ldots, 3 m, 3 m+1\}=T_{14}^{1}$,

$S_{19}^{1}=\{3 m+2\}=T_{15}^{1}$,

$S_{20}^{1}=\{3 m+3,3 m+4\}=T_{16}^{1}$,

$S_{21}^{1}=\{3 m+5,3 m+6, \ldots,(13 m / 4)+1,(13 m / 4)+$

$2\}=T_{17}^{1}$,

$S_{22}^{1} \cup\left(S_{25}^{1} \cup S_{23}^{1}\right) \cup S_{24}^{1}=(13 m / 4)+3,(13 m / 4)+4$,

$(13 m / 4)+5, \ldots,(7 m / 2)-1,(7 m / 2),(7 m / 2)+1=$ $T_{18}^{1}$,

$S_{26}^{1}=\{(7 m / 2)+2\}=T_{19}^{1}$,

$S_{27}^{1}=\{(7 m / 2)+3\}=T_{20}^{1}$.

Notice that $\min \left(T_{i}^{1}\right)=\max \left(T_{i-1}^{1}\right)+1, i=2,3, \ldots, 20$. Moreover, $T_{i}^{1}$ consists of consecutive integers. Simple 
TABLE 1: $S_{8}^{1} \cup S_{9}^{1} \cup S_{10}^{1} \cup S_{11}^{1} \cup S_{12}^{1}$ consists of $3 \mathbf{m} / 12$ consecutive integers.

\begin{tabular}{lcc}
\hline$S_{8}^{1}$ & $S_{9}^{1} \cup S_{12}^{1}$ & $S_{11}^{1} \cup S_{10}^{1}$ \\
\hline $2 m+4$ & $2 m+5$ & $2 m+6=S_{10}^{1}$ \\
$2 m+7$ & $2 m+8$ & $2 m+9$ \\
$2 m+10$ & $2 m+11$ & $2 m+12$ \\
$\ldots$ & $\ldots$ & $\ldots$ \\
$9 m / 4-4$ & $9 m / 4-4$ & $9 m / 4-3$ \\
$9 m / 4-2$ & $9 m / 4-1$ & $9 m / 4$ \\
$9 m / 4+1$ & $9 m / 4+2=S_{12}$ & $9 m / 4+3$ \\
\hline
\end{tabular}

TABLE 2: $\mathbf{S}_{22}^{1} \cup\left(\mathbf{S}_{25}^{1} \cup \mathbf{S}_{23}\right) \cup \mathbf{S}_{24}^{1}$ consists of $3 \mathbf{m} / 12-1$ consecutive integers.

\begin{tabular}{lcc}
\hline$S_{22}^{1}$ & $S_{25}^{1} \cup S_{23}^{1}$ & $S_{24}^{1}$ \\
\hline $13 m / 4+3$ & $13 m / 4+4=S_{23}^{1}$ & $13 m / 4+5$ \\
$13 m / 4+6$ & $13 m / 4+7$ & $13 m / 4+8$ \\
$13 m / 4+9$ & $13 m / 4+10$ & $13 m / 4+11$ \\
$\ldots$ & $\cdots$ & $\ldots$ \\
$7 m / 2-6$ & $7 m / 2-5$ & $7 m / 2-4$ \\
$7 m / 2-3$ & $7 m / 2-2$ & $7 m / 2-1$ \\
$7 m / 2$ & $7 m / 2+1$ & \\
\hline
\end{tabular}

counting shows that $S$ consists of $q$ consecutive integers with $q=3 m+1$. Thus, by Theorem 1 , we conclude that $G$ is super edge-magic total. Moreover, by (iv), we have $f_{1}(u v)=k-\left(f_{1}(u)+f_{1}(v)\right)$ for all $u v \in E(G)$. Hence, the theorem in this case.

Case 1.2: $m \equiv 4 \bmod (12)$

We define

$$
\begin{aligned}
& f_{1}\left(v_{i}\right)=2 m+\left(\frac{i-9}{2}\right), \quad i=5,11,17, \ldots, \frac{m}{2}-9, \frac{m}{2}-3 \\
& f_{1}\left(v_{i}\right)=2 m-\left(i-\frac{3}{2}\right), \quad i=7,13,19, \ldots, \frac{m}{2}-7, \frac{m}{2}-1 \\
& f_{1}\left(v_{i}\right)=2 m-\left(\frac{i-3}{2}\right), \quad i=9,15,21, \ldots, \frac{m}{2}-11, \frac{m}{2}-5 .
\end{aligned}
$$

It can be proved in the same lines as previous proof of Case 1.1 that $S$ is a set of $q$ consecutive integers with $q=3 m+1$. Thus, by Theorem 1 , we conclude that $G$ is super edge-magic total. Hence, the theorem in this case. Case 1.3: $m \equiv 8 \bmod (12)$

We define

$$
\begin{aligned}
& f_{1}\left(v_{i}\right)=2 m+2, \quad i=4, \\
& f_{1}\left(v_{i}\right)=2 m-1, \quad i=5, \\
& f_{1}\left(v_{i}\right)=2 m-4, \quad i=9, \\
& f_{1}\left(v_{i}\right)=2 m, \quad i=7, \\
& f_{1}\left(v_{i}\right)=2 m-3, \quad i=11,
\end{aligned}
$$

$$
f_{1}\left(v_{i}\right)=2 m-\left(\frac{i-9}{2}\right), \quad i=13,19, \ldots, \frac{m}{2}-9, \frac{m}{2}-3,
$$

$$
f_{1}\left(v_{i}\right)=2 m-\left(\frac{i-3}{2}\right), \quad i=15,21, \ldots, \frac{m}{2}-7, \frac{m}{2}-1,
$$

$$
f_{1}\left(v_{i}\right)=2 m-\left(\frac{i-3}{2}\right), \quad i=17,23, \ldots, \frac{m}{2}-11, \frac{m}{2}-5 .
$$

It can be proved in the same lines as the previous proof of Case 1.1 that $S$ is a set of $q$ consecutive integers with $q=3 m+1$. Thus, by Theorem 1 , we conclude that $G$ is super edge-magic total. Hence, the theorem in this case.

Case $2: m \equiv 2 \bmod (4)$

$f_{1}\left(v_{i}\right)=\frac{3 m}{2}+3-\left(\frac{i+1}{2}\right), \quad i=m-1, m-3, \ldots, \frac{m}{2}+6, \frac{m}{2}+4$,

$f_{1}\left(v_{i}\right)=\frac{5 m+6}{4}, \quad i=m$,

$f_{1}\left(v_{i}\right)=\frac{3 m}{2}-\left(\frac{i-6}{2}\right), \quad i=\frac{m}{2}+1, \frac{m}{2}-1, \ldots, 8,6$,

$f_{1}\left(v_{i}\right)=2 m+3-\frac{i}{2}, \quad i=m-2, m-4, \ldots, \frac{m}{2}+5, \frac{m}{2}+3$,

$f_{1}\left(v_{i}\right)=\frac{7 m+14}{4}, \quad i=\frac{m}{2}$.

Case 2.1: $m \equiv 2 \bmod (12)$ 
We define

$f_{1}\left(v_{i}\right)=2 m+\left(\frac{3-i}{2}\right), \quad i=5,11,17, \ldots, \frac{m}{2}-8, \frac{m}{2}-2$,

$f_{1}\left(v_{i}\right)=2 m-\left(\frac{i-3}{2}\right), \quad i=7,13,19, \ldots, \frac{m}{2}-12, \frac{m}{2}-6$,

$f_{1}\left(v_{i}\right)=2 m-\left(\frac{i-9}{2}\right), \quad i=9,15,21, \ldots, \frac{m}{2}-10, \frac{m}{2}-4$,

$f_{1}\left(v_{i}\right)=2 m+2, \quad i=4$.

It can be proved in the same lines as the previous proof of Case 1.1 that $S$ is a set of $q$ consecutive integers with $q=3 m+1$. Thus, by Theorem 1 , we conclude that $G$ is super edge-magic total. Hence, the theorem in this case.

Case 2.2: $m \equiv 6 \bmod (12)$

We define

$f_{1}\left(v_{i}\right)=2 m-\left(\frac{i-9}{2}\right), \quad i=5,11,17, \ldots, \frac{m}{2}-10, \frac{m}{2}-4$

$f_{1}\left(v_{i}\right)=2 m-\left(\frac{i-3}{2}\right), \quad i=7,13,19, \ldots, \frac{m}{2}-8, \frac{m}{2}-2$,

$f_{1}\left(v_{i}\right)=2 m-\left(\frac{i-3}{2}\right), \quad i=9,15,21, \ldots, \frac{m}{2}-12, \frac{m}{2}-6$,

$f_{1}\left(v_{i}\right)=2 m, \quad i=4$.

It can be proved in the same lines as the previous proof of Case 1.1 that $S$ is a set of $q$ consecutive integers with $q=3 m+1$. Thus, by Theorem 1 , we conclude that $G$ is super edge-magic total. Hence, the theorem in this case.

Case $2.3: m \equiv 10 \bmod (12)$

We define

$f_{1}\left(v_{i}\right)=2 m+2, \quad i=4$,

$f_{1}\left(v_{i}\right)=2 m-1, \quad i=5$,

$f_{1}\left(v_{i}\right)=2 m-4, \quad i=9$,

$f_{1}\left(v_{i}\right)=2 m, \quad i=7$,

$f_{1}\left(v_{i}\right)=2 m-3, \quad i=11$,

$$
\begin{aligned}
& f_{1}\left(v_{i}\right)=2 m-\left(\frac{i-9}{2}\right), i=13,19, \ldots, \frac{m}{2}-10, \frac{m}{2}-4 \\
& f_{1}\left(v_{i}\right)=2 m-\left(\frac{i-3}{2}\right), \quad i=15,21, \ldots, \frac{m}{2}-8, \frac{m}{2}-2, \\
& f_{1}\left(v_{i}\right)=2 m-\left(\frac{i-3}{2}\right), \quad i=17,23, \ldots, \frac{m}{2}-12, \frac{m}{2}-6 .
\end{aligned}
$$

It can be proved in the same lines as previous proof of Case 1.1 that $S$ is a set of $q$ consecutive integers with $q=3 m+1$. Thus, by Theorem 1 , we conclude that $G$ is super edge-magic total. Hence, the theorem.

\section{Conclusion}

We are able to prove the cycle book conjecture for $m$ is even, but we cannot prove it for $m \equiv 5 \bmod (8)$. Hence, the cycle book conjecture is an open problem.

\section{Data Availability}

No data were used to support this study.

\section{Conflicts of Interest}

The authors declare that there are no conflicts of interest.

\section{Acknowledgments}

The authors thank Lembaga Penelitian Dan Pengabdian Kepada Masyarakat, Universitas Bengkulu, and Universitas Sebelas Maret, Indonesia, for 2020 National Collaboration Research Grant No. 2063/UN30.15/PG/2020, June 23th, 2020.

\section{Supplementary Materials}

The supporting file 02-OMMITED-PROOF-V1-Revision is needed to support the process of review of article. It contains 5 attachments as follows. Attachment 1: proof of case 1.2; attachment 2: proof of case 1.3; attachment 3: proof of case 2.1; attachment 4: proof of case 2.2; and attachment 5: proof of case 2.3. (Supplementary Materials)

\section{References}

[1] G. Chartrand, L. Lesniak, and P. Zang, Graph and Digraph, CRC Press, Taylor \& francis group, Boca Raton, FL, USA, 5th edition, 2011.

[2] A. Kotzig and A. Rosa, "Magic valuations of finite graphs," Canadian Mathematical Bulletin, vol. 13, no. 4, pp. 451-461, 1970.

[3] H. Enomoto, A. S. Llado, T. Nakamigawa, and G. Ringel, "Super edge-magic graphs," Journal of Mathematics, vol. 34, pp. 105-109, 1998. 
[4] A. A. Bhatti, M. Javaid, and M. Hussain, "On super (a,d)-edgeantimagic magic total labeling of subdivided caterpillar," Utilitas Mathematica.vol. 98, pp. 227-241, 2015.

[5] A. Raheem, M. Javaid, M.A. Umar, and G. C. Lau, "On super (a;d)-eat valuation of subdivided caterpillar," TWMS Journal of Applied and Enginering Mathematics, vol. 9, no. 4, pp. 693-703, 2019.

[6] M. Javaid, A.A. Bhatti, and M. K. Aslam, "Super (a,d)-edge antimagic total labeling of a subclass of trees," AKCE International Journal of Graphs and Combinatorics, vol. 14, pp. 158-164, 2017.

[7] J. A. Gallian, "A dynamic survey: graph labeling, electronic journal of combinatorics, dynamics survey \#DS6," 2019, https://www. combinatorics.org/files/Survey/ds6/ds6v22-2019.pdf.

[8] A. M. Marr and W. D. Wallis, Magic Graphs, Springer Science+ Business Media, Berlin, Germany, 2nd edition, 2013, https://springer.com/gp/book/9780817683900, 2nd edition.

[9] B. Swita, U. Rafflesia, N. Henni Ms, D. S. Adji, and M. Simanihuruk, "On edge magic total labeling of $(7,3)$-cycle books," International Journal of Mathematics and Mathematical Science, vol. 2019, Article ID 1801925, 8 pages, 2019.

[10] K. A. Reddy and S. S. Basha, "Critical set of caterpillar graph for secret sharing scheme based on reverse super edge magic labeling," International Journal of Scientific \& Technology Research, vol. 8, no. 11, pp. 3534-3536, 2019.

[11] C. Imron, B. Setyono, R. Simanjuntak, and E. T. Baskoro, "Critical set of caterpillar graph for secret sharing scheme," Journal of Combinatorial Mathematics and Combinatorial Computing, vol. 65, pp. 121-125, 2008.

[12] E. T. Baskoro, R. Simanjuntak, and M. T. Adithia, "Twolevel secret sharing schemes based on magic labelings," in Proceeding of Indonesia Cryptology and Information Security Conference, INA-CISC2005, Jakarta, Indonesia, March 2005.

[13] J. MacDougall and W. D. Wallis, "Strong edge-magic labeling of a cycle with a chord," Australasian Journal of Combinatorics, vol. 28, pp. 245-255, 2003.

[14] I. Singgih, "Edge magic total labeling of lexicographic product $\mathbf{C}_{4}(2 \mathbf{r}+1) \circ \overline{\mathbf{K}_{2}}$ cycle with chords, unions of paths, and unions of cycles and, cycle with chords, union of paths, union of cycles and paths," Indonesian Journal of Combinatorics, vol. 2, no. 2, pp. 111-122, 2018.

[15] I. Singgih, New Methods for Magic Total Labelings of Graphs, Department of Mathematics and Statistics, Masters Thesis, University of Minnesota, Minneapolis, Minnesota, 2015.

[16] O. Berkman, M. Parnas, and Y. Roditty, "All cycles are edgemagic," Ars Combinatoria, vol. 59, pp. 145-151, 2001.

[17] R. D. Godbold and P. J. Slater, "All cycles are edge-magic," Bulletin of the Institute of Combinatorics and its Applications, vol. 22, pp. 93-97, 1998.

[18] R. M. Figueroa-Centeno, R. Ichishima, and F. A. MuntanerBatle, "The place of super edge-magic labelings among other classes of labelings," Discrete Mathematics, vol. 231, no. 1-3, pp. 153-168, 2001, https://www.sciencedirect.com/science/ articel/pii/S0X00003149.

[19] Y. Yuansheng, X. Yue, X. Xirong, and M. Xinhong, "Super edge magic labelings of book graphs $B_{n}$," Ars Combinatoria, vol. 93, pp. 431-438, 2009.

[20] Y. Yuansheng, X. Yue, X. Xirong, and M. Xinhong, "Super edge magic labelings of book graphs Bn," Ars Combinatoria, vol. 455, 2009. 